\title{
Guest Editorial: Politics and health
}

\author{
DEREK YACH
}

Politics and health have always been intertwined. Mahesh Maskey reminds us of Virchow's famous statements about 'politics as medicine writ large' in describing his own work in Nepal. When political courage, individual commitment, organizational support and financing combine, the health of populations benefits. However, this rarely happens. Rather, advocates for health are destined to struggle for change in settings where other interests often take precedence over health considerations.

This issue of Development describes some of these struggles. Some are intellectual and philosophical. Is the current governance of health satisfactory or has increased pluralism led to a weakening of traditional global health 'leaders' roles? Should primary health care be organized as a set of vertical programmes or comprehensively? Are new public-private partnerships (PPPs) advancing health gains or do they threaten progress? And more practically, why is so little attention given to cardiovascular disease or maternal mortality in global fora where health priorities are considered and where funding decisions are taken? These and many more issues are well described in this edition. There are no simple answers to these questions, but new insights are emerging that should advance action in future.

Global health is now regarded as a major political issue when heads of state meet as the G7 or the G77; when NGOs met at the recent World Social Summit in India; and when leaders of business meet in Davos at the World Economic Forum. This greater attention to health has been brought about by several different forces: the demand for better access to HIV/AIDs treatment by developing countries supported by effective international NGOs; recognition of the value of investing in health as a means of accelerating economic development as stated in the Commission on Macroeconomics and Health; the fear of SARS and other serious infectious disease outbreaks wrecking economies, or undermining security; the need to avoid litigation and a threat to corporate reputations arising from increasing global 'food wars'; and one would hope, a greater realization that better health for all is a right.

For each of the above arguments, there are growing numbers of informed and active players. They include not just the health departments of countries and the World Health Organization (WHO), but a diverse and widening network of players - all of who want

a say in which issues get priority in terms of advocacy, funding and action. They know the stakes are high. The decision to create the Global Fund for AIDS,TB and Malaria led 
to investment of billions of dollars in new programmes - beneficiaries include not just the people with disease, but pharmaceutical companies, governments, academics and NGOs. The impact of the Fund has been to concentrate the minds of many on addressing three diseases. Here, I address a few key issues raised by the authors in this special edition of Development.

\section{Do vertical programmes remain vertical?}

Litsios, Lee and others caution in the journal against vertical approaches to PHC. Litsios outlines in sobering terms the way in which decisions about PHC have been made in the past- and indicates they may be a marker of future actions. Time will tell if the creation of the Global Fund will be at the cost of attention to the broader health agenda or whether, as many proponents of it suggest, it will provide a platform for extending treatment to people for all life-threatening and disabling conditions.

The history of public health suggests that once one starts with specific diseases, the broader expansion to building infrastructure for $\mathrm{PHC}$ is unlikely. Smallpox eradication did not lead to improved vaccine services; rather late in the polio eradication process efforts are being made to ensure that post polio, there will be a strong network of labs to support other disease control programmes - but progress remains slow in doing this; and UNICEF's GOBI-FFF programmes did not expand to take on board other health concerns.

There is still a small window of opportunity to influence the way in which AIDS treatment programmes, like WHO's ' 3 by 5' and others, could act as a stimulus for stronger health systems in countries where HIV/AIDS dominates the health agenda. But to do so will require great skill in convincing the HIV/AIDS control community and all who will gain from its investments that it is in their interests to act differently!

\section{Why not a Global Fund for PHC?}

Imagine if the NGOs supporting the vision of comprehensive PHC as the way to achieve Health for ment for sick patients today - maybe we would have had a Global Fund on PHC instead! And that would have attracted the same set of players to demonstrate innovation and commitment to $\mathrm{PHC}$ as we now have focused on three diseases. Part of the problem is that the global governance of HIV/ AIDS has become so diffuse and complex: WHO, UNAIDS, UNICEF and Global Fund have different governing bodies - all would want to lead on global AIDS policy issues - and then there are major donors, pharmaceutical companies, NGOs of various types, human rights activists and academics who each believe they have the solution to better governance and thereby better decision making in HIV/AIDS.

What is true of HIV/AIDS is increasingly true of many other health issues and of the higher level debates I mentioned above. There has been no significant recent review of the global governance needs of health in decades. The consequence of this is that the turf battles that beset HIV/AIDS beset most other areas of public health, especially those with more funding or political attention. Demands for global health action have increased; funding (excluding HIV/AIDS) has not increased significantly for years. In fact, WHO, as one critical example, has been pinned down on a budget agreed over a decade ago with no immediate prospect of seeing its regular budget increase? When money is tight, and opportunities for action broad, the decisionmaking process becomes critical. Lee alludes to this when stressing the importance of priority setting.

\section{Who should do what in global health?}

A fresh review of major players' mandates and comparative strengths is warranted. This may well conclude that WHO does best when it is in high-level advocacy mode-urging governments to focus on the 'all' in Health for All; calling for an end to the stigma that surrounds mental illhealth; making the case for tackling maternal deaths; disseminating evidence on effective interventions; or when it uses its constitutional right to develop and push for implementation of norms and standards - such as the new Framework Convention on Tobacco Control, the Code of Marketing of Breast-Milk or more effective International 
Health Regulations that deal with infectious disease threats, or could deal with global aspects of food labelling and advertising to children; or when it mobilizes funds and good will to address new threats to health; or when it embarks on eradication programmes and very selectively tackles disease outbreaks like Ebola and SARS.

However, such a review may also conclude that whenWHO tries to control endemic diseases, or tries to engage in building health systems, it stretches itself well beyond its mandate and capabilities. History has shown this to be the case. National health authorities need to lead on these issues and be supported by the widest array of international and national players. And it is in putting together teams of players to jointly address common health problems that we then run into new problems.

\section{Private-public partnerships for health - moving from the ideological to the pragmatic}

Kelley Lee, Kent Buse and Judith Richter in different ways, raise serious concerns about privatepublic partnerships for health. That we need a wider array of players, including sometimes the private sector, is acknowledged by all. What is trickier to decide is when to constitute a formal 'partnership' with some legal basis; when to share funds and joint decision-making outside of the usual governance structures of WHO or national governments; and when to simply interact. What can be done to reform cross-sector partnership? How to achieve the best and most sustainable outcome for all? Richter usefully distinguishes between partnerships based on ideology and principled interactions with business actors that lead to tangible improvements in health.

Health professionals need to be wary of the 'ideological' basis for many partnerships. It comes from certain conservative elements of the business community who believe strongly in deregulation, downsizing government and replacing government laws with industry-led self-regulation. The International Chamber of Commerce have long pushed this cause; as have those corporate interests supported by certain governments who succeeded in making quaintly named 'Type
II' initiatives the major outcome of the World Summit on Sustainable Development. Type II initiatives are voluntary efforts to address development issues freed of government laws and oversight.

At a time when global public health concerns could benefit from stronger guiding laws and policies, not weaker ones, the ideological underpinning of new partnerships needs careful study. We know well that self-regulation failed miserably in the case of tobacco marketing and smoke-free policies; and governments have therefore put in place the FCTC as the first example of a WHO-led treaty. Other areas of public health lend themselves to stronger international norms and standards and in all cases, even discussing possibilities will lead to an outpouring of ideological arguments about why governments and WHO should stay out of this area, the very strength of the opposition being a good way to know if the proposed measure will be effective!

Senator Waxman, Tim Lang and Michael Heasman provide tangible evidence of what happens when WHO raises the spectre of taxing certain foods, restricting food advertising to children and reducing subsidies on agricultural commodities that could be the lifeblood of many developing country economies. They describe how hoards of lobbyists combine with certain governments to thwart introduction of basic health promoting policies by questioning the scientific basis of reports, suggesting that WHO's mandate in dealing with food, tobacco or alcohol should be restricted to education and surveillance, and proposing that unhealthy consumption patterns merely require more personal responsibility.

The FCTC process, as outlined by Collin shows how dialogue on a major public health issue over time leads to increased awareness of the need to address the multisectoral dimensions of the issue. The FCTC sets a high standard for this by including explicit reference to taxes, cross-border and national marketing bans and liability and compensation provisions to apply when industry acts irresponsibly. Some of these elements may well be needed as we start to address the global epidemics of food-related diseases. Progressive food companies support regulations that raise the floor for all companies provided they do not stifle innovation. 
The pragmatic reasons for partnering though should not be dismissed out of hand. Many recently developed partnerships have delivered new money, new energy to old problems, new players, new research and new products needed in developing countries to diagnose and treat disease. While not perfect, the net impact of GAVI, the Global Fund for AIDS, TB and malaria, the Global Forum on Health Research on public health may prove to have been positive over the long term. Clearly, the concerns about governance, and thereby control, outlined by Buse and Richter, need to be evaluated. Part of the problem with some of these initiatives is that they were born in an era of weak global leadership by WHO.

New donors did not trust WHO to deliver services on the ground. And as mentioned earlier, this seems an appropriate concern based on watching WHO's performance over the last 50 years. Despite some who misread its primary function as being operational, WHO was never set up to be a development agency. Its operational functions are carefully delimited in the constitution. Rather it can and should be a more aggressive convenor of the diversity of players who have competence, track records and abilities to deliver together at community level. In doing so, it could more actively ensure that there is an appropriate balance between community-based organizations engaged in initiatives as opposed to governmentand donor-led agencies.

Dr Brundtland acknowledged the importance of balance in her address to the World Health Assembly in 2001. It was an important speech as it laid out several opportunities that were being pursued under the broad rubric of 'partnerships'. She stressed that:

In all partnerships between the public sector, civil society and the private sector, we would like to see the optimal balance of power, representation and influence in order to achieve the best and most sustainable health outcomes possible.

Richter and Buse do not reject PPPs out of hand, nor do they provide many specific ideas about their reform. It would seem that changes are needed at least with respect to WHO's role in PPPs. mandate. It would be within its mandate to provide regularly a succinct overview of PPPs; and of its own significant interactions with industry and other players engaged in health. And to go further, to assess whether these efforts are leading to outcomes in an efficient way, whether certain PPPs should be merged or stopped. In preparing such an annual report, an independent advisory board comprising representatives of government and civil society could be charged with assessing the complex issues of governance, whether the priorities of the PPPs are in accord with those agreed by WHO's Member States and whether the question of conflicts of interest and perceived conflicts of interest are explicitly and regularly addressed. It would report directly to the Director General and its report could be tabled for discussion at meetings of the Executive Board. I have no doubt that many governments and many multinational companies would welcome such an open and transparent process - but a few others, often supported by certain members of the WHO secretariat, would find it threatening to their work.

\section{The restricted focus of global health priorities and of new PPPs}

Most PPPs have focused on a selected number of infectious diseases. Few have addressed maternal deaths, chronic diseases like cardiovascular diseases, cancers or mental health, or injuries. Why have advocates for these conditions not been as vocal or effective in getting their messages through to donors, the media and other decision makers? In the case of maternal deaths, there are few to speak for dead mothers - even the fathers remain silent. Health professionals and some women's groups do try - but often become bogged down by a fear that they would be seen to equate women's health with one specific set of concerns.

Advocacy for better heart health requires addressing strong commercial interests associated with the major risks for CVD: tobacco and diet. Collin has highlighted some of the ways in which many sectors of society mobilized against tobacco; and in recent months, significant progress has been made in starting to address commercial pres- 
sures that have played such a significant role in impeding the process of introducing a global strategy for diet, physical activity and health.

Lang and Heasman urge the public health community to address nutrition issues from an ecological and not an individualized approach. In doing so, agricultural economists need to dispel the incorrect messages circulated by lobbyists about the alleged harm the new WHO diet and physical activity strategy will cause, and show that there will be considerably more winners than losers. By calling for greater worldwide consumption of fruits, vegetables, nuts and grains, WHO is providing the world farming community, particularly important to developing countries, with a powerful argument for its expansion and growth - not contraction! Europe is the largest exporter of white sugar. If the hefty subsidies were removed, imports from developing countries would rise by as much as 500 per cent, global sugar prices would increase by 30 per cent and the livelihoods of farmers in some of the poorest countries would improve as a result.

\section{Cardiovascular diseases kill people in developing countries today}

In addition to addressing commercial pressures, there remain several myths that need to be addressed before CVD and other chronic diseases will be successfully tackled. Susan Raymond and Stephen Leeder provide us with strong arguments that counter some of these myths: CVD impact on the poor not just the affluent; CVD effect people in developing countries during their productive years; CVDs have significant impacts on national and family economies. And importantly, CVD has a very significant direct and indirect impact on women despite this; the International Women's groups remain largely silent about this real killer. Amalia Waxman and Lang effectively counter many arguments advanced by sugar interests for inaction.

John Bowis provides a powerful rationale for investing in mental health programmes and in addressing the severe discrimination and stigma associated with it. His pleas, and those made recently by WHO in its World Health Report of 2001 that focused on mental health, have yet to be translated into new financial support for mental health.

Outside of the narrow range of in vogue health problems, it is almost impossible to get serious funding or political support. As mentioned earlier, the G8 and G77 leaders now address health issues but only the narrow agenda. Even major causes of childhood deaths are rarely considered in highlevel fora.

\section{Global health leadership needs reinvigoration}

Socrates Litsios and Maskey emphasize the role of individual and institutional leadership in setting agendas for public health and gathering support for their implementation. Without Mahler, there would have been no passion, and therefore little support for PHC following Alma Ata. Without Brundtland's political acumen and courage there would have been no FCTC.

At a time when global health is being discussed in settings it has never before reached, the tragedy is that the content and scope of such discussions have become overly restricted to a few diseases and to treatment as the sole solution. Insufficient attention is given to prevention and health promotion, to building health systems and supportive academic and research infrastructure in developing countries. The focus of so many 'health' debates is centred on the prices of a few drugs necessary issues - but not sufficient for the attainment of steadily improving health outcomes in all countries. The seriously neglected area of diet, nutrition and food policy still languishes in a decades' old paradigm.

Global health needs an injection of leadership that will start to reorient the focus from a few diseases, to the broader promotion of health, and recognize that to do so, will require more collaboration between governments, UN agencies, civil society and the private sector that is guided by commitment to a few key values and approaches: equity, gender, human rights, science and sustainability. The Gates Foundation now supports work aimed at addressing certain 'Grand Challenges' in health - most will yield laboratorybased solutions to complex social problems. Now 


\section{Development 47(2): Upfront}

is the time for community-based Grand Challenges to be tackled with as much financial and political support as is being given to tracking down the structure of the SARS virus.

This issue of Development reminds readers that progress in health, and progress in advancing progressive political ideas and values are indivisible. Many of the authors are themselves directly engaged in struggles of which Virchow would have been proud. Whether they are struggles for better human rights in health, or for improving gender equity, or involve addressing neglected diseases and their risk factors, or for exposing how special interests have distorted the public health agenda, all describe deep commitment to work towards Health for All. At 25 years after Alma Ata, the flame of hope given to the world health community remains strong - action must follow. 